\title{
Avaliação de professores nas escolas públicas portuguesas
}

Isabel Tomás*

Jorge Adelino Costa"

\section{Resumo}

0 modelo de avaliação de professores da escola pública portuguesa sofreu, a partir de 2007, profundas alterações. As mudanças ocorridas, numa lógica política de intensificação dos processos de avaliação entendidos como elementos estratégicos para a implementação da qualidade na administração pública, em geral, e nos sistemas educativos, em particular, foram objecto de muita contestação por parte da classe docente portuguesa. Esta contestação levou a que o poder político fosse introduzindo várias modificações no modelo de avaliação de desempenho docente inicialmente proposto. São os traços gerais que caracterizam este modelo, tendo em conta as alterações introduzidas nos últimos quatro anos, bem como algumas apreciações sobre o modo como o processo decorreu, que pretendemos descrever no presente artigo.

Palavras-chave: Avaliação de professores. Escola pública. Portugal.

\section{The evaluation of teachers in Portuguese public schools}

\section{Abstract}

The evaluation model of Portuguese public school teachers has, since 2007, undergone deep changes. The modifications that have occurred were the reflex of a political logic of strengthening of the evaluation procedures - seen as strategic elements for the implementation of quality in public administration, in general, and, in public educational systems, in particular. These changes were the subject of much dispute on the part of the Portuguese teachers. This contestation has led to the introduction of several changes in the model of

\footnotetext{
Doutoranda em Educação, Instituto de Educação da Universidade de Lisboa, Portugal.

E-mail: isabelcpt@yahoo.com

*. Doutor em Educação; Professor Catedrático da Universidade de Aveiro, Portugal. E-mail: jcosta@ua.pt
} 
teacher performance evaluation as it was initially proposed. In this article we intend to describe the broad features that characterize this model, taking into account the modifications that have been introduced in the last four years, as well as some reflections on the development of the process of implementation of this model of teacher evaluation.

Keywords: Teacher evaluation. Public school. Portugal.

\section{Evaluación de los profesores portugueses en las escuelas públicas Resumen}

El modelo de evaluación para los maestros de escuelas públicas en Portugal ha experimentado, desde 2007, cambios profundos. Los cambios, en una lógica política de la intensificación de los procedimientos de evaluación, son entendidos como elementos estratégicos para la implementación de la calidad en la administración pública en general y en los sistemas educativos, en particular, y han sido muy cuestionados por los maestros portugueses. Esta pelea ha llevado el poder político a la introducción de varias modificaciones en el modelo de evaluación del desempeño docente propuesto inicialmente. Son los rasgos generales que caracterizan a este modelo, teniendo en cuenta los cambios en los últimos cuatro años, y algunas consideraciones de cómo el proceso se desarrolló, que se pretende describir en este artículo.

Palabras clave: Evaluación de profesores. Escuela pública. Portugal.

\section{Introdução}

Após a II Guerra Mundial, a maioria dos paises ocidentais levou a cabo reformas profundas nos seus sistemas educativos. Alargaram o número de anos de ensino obrigatório, estabeleceram distinções entre os vários niveis de ensino ainda que promovendo a sua articulação, diversificaram a oferta formativa do ensino secundário com a introdução, designadamente, do ensino técnico e profissional, quer para dar resposta à necessidade de mão-de-obra especializada, quer para responder a uma população escolar cada vez mais heterogénea. Além da reforma das escolas e dos curriculos houve, conjuntamente, uma preocupação generalizada com a formação de professores qualificados (BENAVOT; RESNIK, 2006).

Em Portugal este espírito reformista tem maior visibilidade a partir da década de 70 do séc. XX. A democratização do ensino e o alargamento do ensino obrigatório levaram a que uma das prioridades fosse o investimento na formação inicial dos professores, dada a necessidade de dar resposta à crescente procura da escola. No início da década de 90 a prioridade dada à formação de professores começa a ser progressivamente substituida pela necessidade de dar resposta à cada vez maior 
exigência à qualificação da educação, traduzida na melhoria da qualidade das aprendizagens dos alunos. Uma das estratégias utilizadas para promover e monitorizar a qualidade tem incidido sobre a avaliação, desde a avaliação das aprendizagens, dos currículos, das escolas e, ultimamente, da avaliação do desempenho docente.

Esta mudança paradigmática, extensivel aos outros sectores sob a administração do Estado, tem ocorrido lentamente. Se após a revolução de 1974 a perspectiva dominante ia no sentido de reforçar o papel do Estado e alargar o sector público, esta perspectiva foi, entretanto, substituida pela intenção de melhorar a produtividade e reduzir o peso do sector público na economia. A introdução de dispositivos de monitorização e controlo, nomeadamente através da avaliação do desempenho, decorre também das pressões econômicas e sociais no sentido da modernização sustentada do Estado e do aumento da eficiência e eficácia dos serviços públicos (BOUCKAERT, 1998), incluindo-se nesta tendência também a educação.

\section{Sistema de avaliação do desempenho dos trabalhadores da administração pública portuguesa}

Bilhim (1998) identifica dois possiveis modelos de avaliação do desempenho: a avaliação pelos processos e a avaliação pelos resultados. No primeiro caso, a avaliação está centrada na forma como os programas de acção na administração pública são desenvolvidos, focalizando o processo em detrimento dos resultados finais. No segundo caso, a avaliação procura medir a diferença entre os resultados alcançados e os objectivos previamente estipulados. Nesta última situação, a avaliação pode ser realizada atendendo aos níveis de eficiência e eficácia, isto é, confrontando os recursos mobilizados na consecução dos objectivos pré-estabelecidos (relação custo/benefício) e na medição do desvio entre os objectivos perseguidos e os resultados efectivamente alcançados.

Em Portugal, dada a natureza dos serviços na administração pública, o mecanismo de avaliação adoptado baseia-se na avaliação pelos resultados. Neste âmbito, a avaliação é, igualmente, assumida como um instrumento de gestão, uma vez que pode dar lugar à correcção dos elementos que provocaram um desvio negativo entre o resultado final e a missão que determinou a existência de determinado sector da administração pública (GAMEIRO, 1998).

Ao importar para a administração pública conceitos como concorrência interna e externa abriu-se o caminho para metodologias de avaliação há muito utilizadas no sector privado. É o caso do benchmarking (indicadores que permitem a comparação com organizações consideradas de topo), bem como o recurso a balanced scorecard (BILHIM, 1998). Porém, como refere Bouckaert (1998, p. 62), a utilização destas metodologias de avaliação "não resolve o problema de se saber qual o melhor tipo de avaliação ou quais os indicadores que devem ser escolhidos". Segundo o mesmo autor, 
esta é uma das questões a ser ultrapassada na implementação de um sistema de avaliação na administração pública. Outro problema está relacionado com a legitimidade, uma vez que para ser bem sucedida, a avaliação deve contar com o apoio daqueles a quem se aplica. Por último, a implementação de sistemas de avaliação seguros e práticos requer um sistema convergente de avaliação do desempenho em todos os sectores públicos. Neste sentido, a avaliação não constitui apenas uma questão técnica mas é também um processo valorativo e consequentemente político.

No que concerne ao sistema de avaliação do desempenho na administração pública em Portugal, foi publicada em 2004 o Sistema Integrado de Avaliação do Desempenho na Administração Pública (Siadap), Lei n. 10 (PORTUGAL, 2004), alterada pela Lei n. ${ }^{\circ}$ 66-B (PORTUGAL, 2007a). Este Sistema tem por objectivo o desenvolvimento de um modelo global de avaliação, coerente, aplicável à avaliação dos serviços sob administração directa do Estado, dirigentes e trabalhadores da administração pública, que contribua para a melhoria do desempenho e qualidade do serviço, para aumentar a motivação profissional e o desenvolvimento de competências (PORTUGAL, 2007a). 0 Siadap constitui, deste modo, um sistema convergente de avaliação do desempenho na administração pública, transversal a todos os serviços e organismos, e funcionários.

Os princípios orientadores do Siadap são a avaliação pelos resultados, como meio de atingir a excelência e a melhoria da qualidade dos serviços prestados, assumindo-se como um instrumento de orientação, avaliação e desenvolvimento dos dirigentes, trabalhadores e equipas para a obtenção de resultados e para a demonstração de competências profissionais.

Constituem alguns objectivos do Siadap, a melhoria da gestão da administração pública, adequando a actividade dos serviços com os objectivos das políticas públicas; desenvolver e consolidar práticas de avaliação e auto-regulação da administração pública; identificar as necessidades de formação e desenvolvimento profissional adequadas à melhoria do desempenho; promover a motivação e o desenvolvimento de competências e qualificações, favorecendo a formação ao longo da vida; desenvolver uma cultura de excelência e qualidade; melhorar os processos na óptica do tempo, custo e qualidade; melhorar a prestação de informação e a transparência da acção dos serviços da administração pública; apoiar o processo de decisões estratégicas através da informação relativa a resultados e custos (PORTUGAL, 2007a).

0 processo de avaliação do desempenho para os trabalhadores da administração pública prevê a confrontação entre os objectivos fixados e os resultados obtidos, incidindo igualmente sobre as competências demonstradas ou a desenvolver no exercicio de funções. A avaliação final resulta da ponderação das pontuações obtidas nestes dois parâmetros de avaliação, sendo, no entanto, expressa por menções qualitativas que deverão respeitar valores de percentagens máximas previstas para cada serviço (PORTUGAL, 2007a). 
Os intervenientes no processo de avaliação são o avaliador, o avaliado, o conseIho coordenador de avaliação, a comissão paritária e o dirigente máximo do serviço. 0 avaliador deverá negociar os objectivos e competências com o avaliado, rever regularmente os objectivos negociados e se necessário reformulá-los, avaliar os trabalhadores directamente subordinados, ponderar as expectativas dos trabalhadores na identificação de necessidades de desenvolvimento, e fundamentar as avaliações de desempenho. 0 avaliado deverá proceder à sua auto-avaliação e negociar com o avaliador os objectivos e as competências que constituem os parâmetros de avaliação. 0 conselho coordenador de avaliação é responsável, entre outros aspectos, pelo estabelecimento de orientações gerais que permitam estabelecer objectivos, escolher as competências, e estabelecer os indicadores de medida que permitam caracterizar a situação de cada avaliado. Compete ainda ao conselho coordenador de avaliação validar as avaliações de desempenho relevante e desempenho inadequado e proceder ao reconhecimento do desempenho excelente. A comissão paritária é um órgão consultivo que aprecia as propostas de avaliação antes da sua homologação. 0 dirigente máximo do serviço garante a adequação do sistema de avaliação, coordena o processo, assegura o cumprimento das percentagens para os diferentes desempenhos e homologa as avaliações (PORTUGAL, 2007a).

0 processo de avaliação, cuja periodicidade é anual, compreende as seguintes fases: planeamento do processo de avaliação e definição dos objectivos a atingir; realização da auto-avaliação e avaliação; harmonização das propostas de avaliação com a respectiva contratualização dos objectivos; reunião entre avaliador e avaliado para fixação de competências, avaliação do desempenho e respectivos indicadores; validação das avaliações e reconhecimento de desempenhos excelentes; apreciação do processo de avaliação pela comissão paritária; homologação; reclamações e outras impugnações; e monitorização e revisão dos objectivos (PORTUGAL, 2007a).

Os efeitos decorrentes do processo de avaliação individual são a identificação das potencialidades do trabalhador que devem ser desenvolvidas ou melhoradas, a identificação das necessidades de formação, a melhoria dos processos associados ao desempenho do avaliado, a progressão na carreira ou a atribuição de prémios de desempenho (PORTUGAL, 2007a)

A Portaria n. 1.633 (PORTUGAL, 2007c), de 31 de Dezembro, aprova os modelos de fichas de auto-avaliação e avaliação do desempenho, de monitorização do desempenho, e de reformulação dos objectivos. A referida portaria aprova, ainda, as competências a desenvolver por cada grupo de trabalhadores (pessoal dirigente, técnico superior ou técnico, administrativo, e pessoal operário e auxiliar).

Conforme referido no (PORTUGAL, 2007a), o Siadap articula-se com o sistema de planeamento de cada ministério; contudo, deverão ser sempre respeitados os 
princípios orientadores, isto é, a avaliação do desempenho baseada na confrontação entre os objectivos fixados e os resultados obtidos, as competências demonstradas e a desenvolver, e a diferenciação dos desempenhos sujeita a percentagens máximas para atribuição das menções de desempenho relevante e excelente.

A pressão no sentido da melhoria da gestão pública concentrou esforços no aumento da eficiência e da eficácia dos serviços. 0 dispositivo de controlo assenta na prestação de contas, isto é, a avaliação baseada na monitorização dos desempenhos aliada a sistemas de penalização ou recompensas. Neste campo, os sistemas escolares não constituem excepção. As escolas e os professores estão a ser, cada vez mais, afectados pelas exigências e contingências da avaliação como mecanismo de prestação de contas.

\section{A avaliação do desempenho docente: a Lei de Bases do Sistema Educativo (1986) a 2007}

As primeiras referências à avaliação dos professores podem ser encontradas na Lei de Bases do Sistema Educativo, Lei n. ${ }^{\circ} 46$ (PORTUGAL, 1986), de 14 de Outubro, com alterações introduzidas pela Lei n. ${ }^{\circ} 9$ (PORTUGAL, 2005), de 30 de Agosto, que refere que a progressão na carreira docente deve estar ligada "à avaliação de toda a actividade desenvolvida, individualmente ou em grupo, na instituição educativa" (PORTUGAL, 2005, art. 36. ${ }^{\circ}$, n. 2). 0 Estatuto da Carreira dos Educadores de Infância e dos Professores dos Ensinos básico e Secundário (ECD) aprovado posteriormente pelo Decreto-Lei n. ${ }^{\circ}$ 139-A/90 (PORTUGAL, 1990), dá corpo a esta necessidade de avaliação da actividade docente. No n. 2 do artigo 39. ${ }^{\circ}$ (PORTUGAL, 1990), refere-se que "a avaliação do desempenho do pessoal docente visa a melhoria da qualidade da educação e ensino ministrados" e, nos objectivos da avaliação enunciados no n. ${ }^{0} 3$, encontra-se, entre outros, a melhoria da acção pedagógica e da eficácia profissional dos docentes.

Em 1992 é regulamentado o primeiro regime de avaliação de desempenho docente através do Decreto Regulamentar n. ${ }^{0}$ 14/92 (PORTUGAL, 1992b), de 4 de Julho, que determinava os procedimentos a adoptar na consecução do processo de avaliação. De acordo com este decreto regulamentar, a avaliação do desempenho docente seria um processo periódico que teria lugar no final de cada módulo de tempo de serviço, isto é, no final de cada escalão (períodos de dois, três, quatro ou cinco anos de serviço docente, num total de 10 escalões (PORTUGAL, 1999). Para dar início ao processo de avaliação o docente deveria entregar, ao órgão de gestão da escola, um relatório crítico da actividade por si desenvolvida no período de tempo ao qual reportava a avaliação do desempenho, no qual deveriam ser referidos os seguintes aspectos: serviço distribuído; relação pedagógica com os alunos; cumprimento dos programas curriculares; desempenho de cargos directivos e pedagógicos, participação em 
projectos e actividades desenvolvidas no âmbito da comunidade educativa; acções de formação frequentadas e unidades de crédito obtidas nas mesmas; contributos inovadores no processo de ensino/aprendizagem; estudos realizados e trabalhos publicados (PORTUGAL, 1992b). No que concerne à formação contínua, o docente deveria frequentar acções de formação que lhe permitissem a aquisição de um número mínimo de créditos equivalente ao número de anos que permanecia em cada escalão. $A$ certificação das acções de formação contínua deveria acompanhar o respectivo relatório crítico da actividade docente (PORTUGAL, 1992b).

A avaliação do desempenho docente expressava-se através das menções qualitativas de Satisfaz ou Não Satisfaz. A menção Não Satisfaz seria atribuída em situações em que comprovadamente se verificasse a existência de apoio insuficiente ou má relação com os alunos, a recusa ou mau desempenho de cargos para os quais o docente havia sido nomeado ou eleito, assim como a não conclusão das acções de formação a que tivesse acesso no módulo de tempo de serviço em avaliação (PORTUGAL, 1990). A atribuição da menção Não Satisfaz seria da competência de um júri de avaliação, de âmbito regional, constituído por um representante da respectiva Direcção Regional de Educação (DRE), um elemento do órgão pedagógico da escola onde o docente em avaliação exercia funções e um elemento da Inspecção Geral do Ensino (PORTUGAL, 1990). A menção Satisfaz dependeria do cumprimento dos requisitos necessários à avaliação e permitiria a progressão ao escalão seguinte na carreira docente.

Organizada desta forma, a avaliação do desempenho docente pretendia atingir um duplo objectivo: o desenvolvimento profissional e a regulação da progressão na carreira. No que concerne a este segundo aspecto, o Decreto-Lei n. ${ }^{\circ}$ 139-A/90 (PORTUGAL, 1990), estipulava que os docentes, para ascenderem ao $8 .^{\circ}$ escalão da carreira, estruturada em 10 escalões (PORTUGAL, 1989), deveriam ser sujeitos a uma prova pública, à qual se candidatavam voluntariamente. Nesta prova seria avaliado, por um júri, o currículo do docente e um trabalho de natureza educacional (PORTUGAL, 1992a). Por sua vez o júri, nomeado por despacho do Ministério da Educação, seria constituído por individualidades de reconhecido mérito no domínio da educação e ensino e um docente do mesmo nivel de ensino e grupo de recrutamento do candidato.

Simões (1998, p. 241) realizou um estudo sobre a implementação deste primeiro regime de avaliação do desempenho docente, no qual concluiu que a avaliação de professores "não avaliava". Segundo constatou, a avaliação era encarada pelos professores como uma tarefa burocrática, os relatórios críticos da actividade docente não eram analisados e a classificação de Satisfaz resultava apenas do cumprimento dos requisitos legais, nomeadamente, da realização das acções de formação contínua. Concluiu, ainda, que a formação contínua exercia pouca influência sobre o desenvolvimento profissional dos professores (SIMÕES, 1998). 
A prova pública de acesso ao $8 .^{\circ}$ escalão constituía um mecanismo de diferenciação que considerava o mérito como elemento de selecção no acesso ao topo da carreira. Todavia, esta prova não tinha associado qualquer conteúdo funcional específico, isto é, a transição para escalões superiores não acarretava o desempenho de funções específicas como, por exemplo, a coordenação das estruturas de gestão intermédia (FORMOSINHO; MACHADO, 2010). Além disso, a sua inclusão numa carreira que até então se percorria de forma automática tornou-a alvo de grande contestação por parte dos docentes, acabando por desaparecer.

No final da década de 1990 é alterado o ECD, Decreto-Lei n. ${ }^{1}$ /98 (PORTUGAL, 1998a), que em termos de avaliação do desempenho docente coloca a tónica no mérito e no reforço da profissionalidade docente, bem como na melhoria da qualidade das escolas. Esta mesma referência é feita no preâmbulo do Decreto Regulamentar n. 11/98 (PORTUGAL, 1998b), de 15 de Maio, que passou a regulamentar a avaliação do desempenho. As alterações introduzidas não são substanciais. 0 processo de avaliação continuava a realizar-se no final de cada módulo de tempo de serviço, isto é, no final de cada escalão e a ter por base o relatório de reflexão crítica sobre a actividade desenvolvida durante o período de tempo ao qual reportava a avaliação do desempenho. 0 relatório deveria contemplar determinados aspectos (muito semelhantes ao previsto anteriormente), a saber: serviço distribuído; relação pedagógica com os alunos; cumprimento dos núcleos essenciais dos programas curriculares; desempenho de outras funções educativas, designadamente de administração e gestão escolares, de orientação educativa e de supervisão pedagógica; participação em projectos e actividades desenvolvidas no âmbito da comunidade educativa; acções de formação frequentadas e respectivos certificados; estudos realizados e trabalhos publicados (PORTUGAL, 1998b). Este relatório seria alvo de apreciação pelo órgão de gestão da escola onde o docente se encontrava a exercer funções, tendo em conta o parecer de uma comissão especializada constituída por membros do conselho pedagógico da escola (PORTUGAL, 1998b). Um dos membros desta comissão - o relator - deveria apresentar uma proposta de avaliação resultante da análise do trabalho desenvolvido pelo professor durante o período em avaliação.

Após cumpridas estas formalidades, a avaliação do desempenho docente seria expressa em menções qualitativas de Bom, Satisfaz ou Não Satisfaz. Mantinhamse as condições conducentes à menção qualitativa de Não Satisfaz preconizadas pelo anterior regime de avaliação, sendo esta atribuída, sob recomendação do Presidente do Conselho Executivo da Escola, por uma Comissão de Avaliação de âmbito regional constituida por um docente designado pelo órgão pedagógico da escola em que o docente exercia funções, um representante da respectiva Direcção Regional de Educação e um docente ou individualidade de mérito reconhecido no âmbito da educação designado pelo docente em avaliação (PORTUGAL, 1998b). A menção Não Satisfaz implicaria a não progressão na carreira e deveria ser acompanhada por um programa de desenvolvimento profissional (PORTUGAL, 1998a). 
As menções de Satisfaz e Bom permitiam a progressão ao escalão seguinte. Para obter a menção qualitativa de Bom, o docente, após a obtenção da menção Satisfaz, deveria requerer a apreciação, por uma Comissão de Avaliação de características semeIhantes à comissão de análise da menção de Não Satisfaz, de um documento de reflexão crítica sobre o seu desempenho, no período de tempo de serviço a que se reportou a avaliação. Após a apreciação deste documento, a Comissão de Avaliação deliberaria sobre a atribuiç̧ão da menção de Bom ou sobre a manutenção da menção de Satisfaz (PORTUGAL, 1998b). No caso de ser atribuída a menção de Bom, após quinze anos de serviço, o docente poderia requerer a classificação de Muito Bom, a qual poderia conduzir à bonificação de dois anos na progressão na carreira (PORTUGAL, 1998a).

Ana Curado (2004) analisa a implementação da avaliação de desempenho docente em Portugal incidindo, sobretudo, no Decreto Regulamentar n.o 11/98 (PORTUGAL, 1998b). Entre as opiniões negativas, expressas pelos docentes no âmbito deste estudo, está o facto de o documento de reflexão crítica ser encarado como um pro forma realizado para progredir na carreira. Constatou-se, nesta investigação, que a maioria dos documentos produzidos pelos docentes possuía características descritivas sendo pouco reflexivos. Acresce, ainda, 0 facto de os docentes não serem obrigados a comprovar as asserções feitas no documento, nem a reflectirem sobre o sucesso dos seus alunos. Quanto ao papel das comissões especializadas, constituídas por colegas, verificou-se que não podiam analisar ou discutir as práticas lectivas dos professores, uma vez que os momentos de apreciação estavam limitados à análise dos documentos de reflexão crítica. A diferenciação dos docentes, segundo o seu mérito, era quase impossivel pois as avaliações encontravam-se limitadas à atribuição da menção qualitativa de Satisfaz. Para ver o seu mérito recompensado os docentes teriam de requerer a reapreciação da sua avaliação. Ana Curado (2004, p. 294-295) conclui que

[...] a política de avaliação de professores foi formulada como uma asserção política destinada a confirmar os objectivos políticos e sociais de promoção do consenso e melhoria de qualidade educacional. Contudo a sua eficácia tem sido limitada pela ausência de várias componentes que a literatura sugere serem indispensáveis ao desenvolvimento dos professores e das escolas. [...] Em geral, a política de avaliação de professores tem sido encarada como um instrumento para a progressão na carreira e não como uma forma de promover o desenvolvimento dos professores e das escolas.

\section{Um novo modelo de avaliação do desempenho docente: o período de 2007 a 2009}

0 modelo de avaliação do desempenho docente instituído em Portugal a partir de 2007 tem por base, de acordo com o respectivo Estatuto da Carreira Docente do Decreto-Lei n. ${ }^{15 / 2007}$ (PORTUGAL, 2007b), os princípios e objectivos do Siadap. Os princí- 
pios orientadores são a avaliação pelos resultados, como meio de atingir a excelência e a qualidade dos serviços prestados. Neste sentido, o Siadap assume-se como um instrumento de orientação, avaliação e desenvolvimento, para a obtenção de resultados e para a demonstração de competências profissionais. A avaliação final é expressa através de menções qualitativas, cuja atribuição deverá, no caso das menções superiores, respeitar valores de percentagens máximas relativas à diferenciação dos desempenhos.

As alterações ao Estatuto da Carreira Docente introduzidas em 2007, no que à avaliação diz respeito, correspondem à adaptação dos princípios do Siadap à avaliação dos professores:

A avaliação do desempenho do pessoal docente visa a melhoria dos resultados escolares dos alunos e da qualidade do serviço educativo e das aprendizagens e proporcionar orientações para o desenvolvimento pessoal e profissional no quadro de um sistema de reconhecimento do mérito e da excelência (PORTUGAL, 2007b, art. 40, n. 2).

Assim, o regime de avaliação de professores, regulamentado pelo Decreto Regulamentar n. ${ }^{\circ}$ 2/2008 (PORTUGAL, 2008), concretizava-se em ciclos de dois anos durante os quais o desempenho é aferido através da sua apreciação em quatro dimensões: a) vertente profissional, social e ética; b) desenvolvimento do ensino e da aprendizagem; c) participação na escola e relação com a comunidade educativa; d) desenvolvimento e formação profissional ao longo da vida.

A apreciação do desempenho dos professores nestas quatro dimensões consubstanciava-se em duas componentes: i) uma, da responsabilidade do coordenador de departamento curricular, que tem a ver com o desempenho científico-pedagógico do docente e que compreende a preparação e organização das actividades lectivas e o desempenho na sala de aula, a relação pedagógica com os alunos e a avaliação das aprendizagens; ii) outra, da responsabilidade da Direcção Executiva da escola, tendo em conta a componente funcional do desempenho e que incide sobre a assiduidade, o cumprimento do serviço distribuído, o progresso dos resultados escolares dos alunos e redução do abando, o desempenho de cargos ou funções de natureza pedagógica, a formação contínua e o contributo do professor para o cumprimento dos objectivos da escola através, entre outros aspectos, da sua participação em projectos e em actividades (PORTUGAL, 2008).

Entretanto, alguns destes procedimentos foram simplificados ainda durante este $1{ }^{\circ}$ ciclo de avaliação. Assim, os docentes puderam optar por ser, ou não, avaliados na componente científico-pedagógica, embora este procedimento fosse condição necessária para aceder às menções de Muito Bom e Excelente. Itens como os resultados dos alunos e abandono escolar também não foram considerados no $1 .{ }^{\circ}$ ciclo de avaliação do desempenho docente (PORTUGAL, 2009b). 
No que respeita aos intervenientes no processo, além do professor avaliado, previa-se a intervenção de mais três participantes, conforme esquematizado na Figura 1.

Figura 1. Intervenientes na aplicação do $1 .{ }^{\circ}$ ciclo de avaliação do desempenho docente.

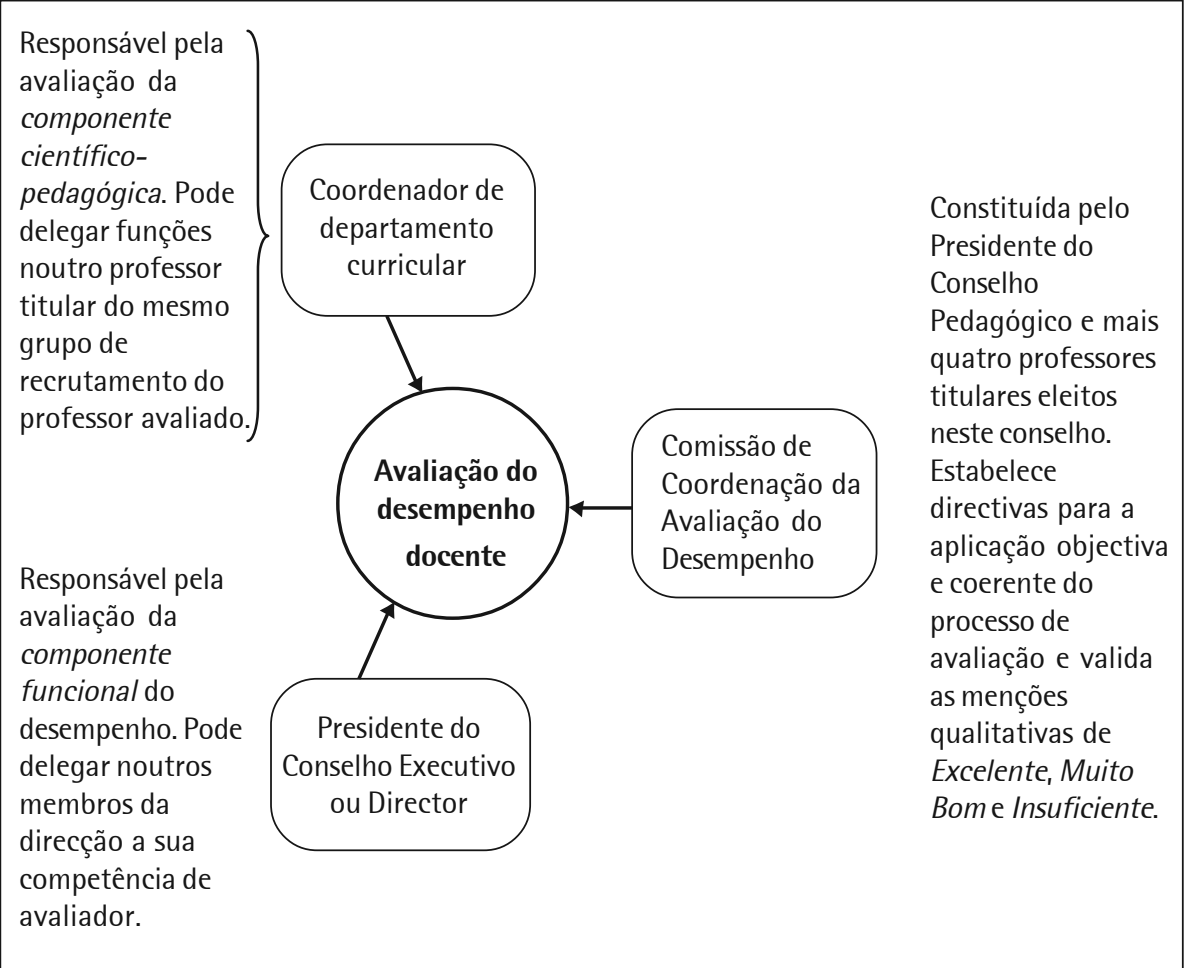

Fonte: Portugal (2008a, art. 12. $\left.{ }^{\circ}, 13 .^{\circ}\right)$.

De acordo com o esquema apresentado, a comissão de coordenação da avaliação do desempenho estabelecia, em cada escola, as directivas que conduziam à aplicação do modelo de avaliação. Todavia, uma vez que o modelo se baseava em procedimentos de recolha de informação sobre o desempenho dos professores, foi necessário construir instrumentos de registo que permitissem a execução desta tarefa, o que constituía uma incumbência do Conselho Pedagógico (PORTUGAL, 2008a). Sempre que houve lugar à avaliação da componente científico-pedagógica do desempenho do professor, esta foi assegurada pelo coordenador do departamento ou por um professor titular do mesmo grupo de recrutamento do professor avaliado. Apenas em caso excepcionais, isto é, sempre que não foi possivel nomear um professor titular do mesmo grupo de recrutamento do professor avaliado, procedia-se à nomeação de professores avaliadores em comissão de serviço. A componente funcional do desempenho docente foi avaliada por um elemento da direcção da escola. 
0 processo de avaliação iniciava-se com a apresentação, pelo professor avaliado, de uma proposta de objectivos individuais que posteriormente poderiam ser negociados com os avaliadores. Os objectivos eram fixados por referência ao apoio prestado aos alunos, à participação nas estruturas de orientação educativa e nos órgãos de gestão, à relação com a comunidade, à formação contínua e à participação e dinamização de actividades ou projectos, considerando em todos estes aspectos as metas e objectivos do Projecto Educativo de Escola e Plano Anual ou Plurianual de Actividades (PORTUGAL, 2008a).

Uma vez no final do ciclo avaliativo, o professor avaliado preenchia a ficha de auto-avaliação, explicitando o seu contributo para a consecução dos objectivos individuais fixados (PORTUGAL, 2008a). Em algumas escolas, a auto-avaliação do professor foi complementada pela entrega de um portfolio individual do Conselho Científico para a Avaliação de Professores (CCAP) (PORTUGAL, 2010a). Após este procedimento e tendo em conta toda a informação recolhida, os avaliadores preenchiam as fichas de avaliação (PORTUGAL, 2008b), alterado pelo Despacho n. ${ }^{\circ}$ 3006/ 2009 (PORTUGAL, 2009c), de 23 de Janeiro. 0 resultado final derivava da média das pontuações obtidas em cada uma das fichas de avaliação expressa de acordo com a correspondência descrita no Quadro 1, estando a atribuição das menções de nível superior, Excelente e Muito Bom, sujeita a um regime de percentagens máximas para a diferenciação do desempenho.

Quadro 1: Correspondência entre a avaliação qualitativa e quantitativa ( . $^{\circ} 2$ do art. 46 do Decreto-Lei n. ${ }^{\circ}$ 15/2007, de 19 de Janeiro).

\begin{tabular}{|c|c|}
\hline Menções qualitativas & Avaliação quantitativa (valores) \\
\hline Excelente & $\geq 9$ \\
\hline Muito Bom & $8-8,9$ \\
\hline Bom & $6,5-7,9$ \\
\hline Regular & $5-6,4$ \\
\hline Insuficiente & $<5$ \\
\hline
\end{tabular}

Fonte: Os autores (2011).

A aplicação deste regime de avaliação do desempenho docente foi acompanhada por niveis elevados de contestação por parte dos professores e de significativa polémica no seio das escolas e nos meios político-sociais, tornando-se um "assunto nacional". Vários estudos foram também canalizados para a análise deste tema, sendo de destacar os relatórios apresentados pela Consultora Deloitte (2009), pelo Conselho Científico para a Avaliação de Professores (PORTUGAL, 2009a, 2010a) e pela Organização para a Cooperação e Desenvolvimento Económico (OCDE) - Organisation for Economic Co-Operation and Development (2009) - todos dirigidos à apreciação da implementação deste $1 .^{\circ}$ ciclo de avaliação do desempenho docente. No ponto seguinte iremos descrever algumas destas apreciações. 


\section{Fatores que influenciaram a aplicação do modelo de avaliação}

As mudanças introduzidas na avaliação do desempenho docente (postas em prática no biénio 2007-2009) ocorreram fundamentalmente no quadro de uma visão top-down da decisão política, por vontade da administração central, em nome dos seus valores e objectivos (LASCOUMES; LE GALĖS, 2007). As tensões e dilemas que se geraram com a aplicação do modelo de avaliação deram origem a uma onda de contestação de tal forma que "a sua implementação constituiu um acontecimento, um facto e não um processo" (FLORES, 2009, p. 241).

Os vários estudos realizados sobre a aplicação do modelo de avaliação no biénio 2007-2009 identificaram as alterações ao Estatuto da Carreira Docente como dos principais factores de constrangimento. A questão central prendeuse com a reestruturação da carreira docente, numa lógica de verticalização, através da diferenciação funcional, nomeadamente no que respeita ao desempenho de cargos especializados. Assim, em 2007, a carreira docente foi estruturada em função de duas categorias - professor e professor titular, em que as funções de avaliador (do desempenho docente) seriam exercidas por docentes com a categoria de professor titular. Apenas em casos excepcionais, as funções de avaliador seriam exercidas por professores nomeados em comissão de serviço. Esta situação gerou desconforto e uma onda de contestação. Por um lado, os docentes contestavam o modo como decorreu o concurso de acesso à categoria de professor titular, por outro lado, e de certo modo na sequência desse concurso, os docentes avaliados não reconheciam legitimidade aos avaliadores, especialmente, quando estava em causa a avaliação na componente científicopedagógica e a correspondente observação de aulas (DELOITTE, 2009; PORTUGAL, 2009a; ORGANISATION FOR ECONOMIC CO-OPERATION AND DEVELOPMENT, 2009). De acordo com o estudo da OCDE, alguns professores titulares confessaram a sua "falta de motivação, competência e preparação" para o desempenho desta tarefa (ORGANISATION FOR ECONOMIC CO-OPERATION AND DEVELOPMENT, 2009, p. 39). De facto, neste campo, a falta de formação considerada adequada ao desempenho da função de avaliador foi uma das fragilidades apontadas ao actual modelo de avaliação. Segundo a OCDE, a pouca formação disponibilizada não focou aspectos essenciais, tais como: "a partilha de responsabilidade pela qualidade do ensino e dos resultados dos alunos, a compreensão dos indicadores que compõem o bom ensino e como utilizar o feedback de forma eficaz" (ORGANISATION FOR ECONOMIC CO-OPERATION AND DEVELOPMENT, 2009, p. 41).

Outra questão que contribuiu, a montante, para o clima de contestação e dificultou a organização do modelo de avaliação nas escolas foi a prescrição de 
prazos demasiado curtos para a criação do dispositivo de avaliação (DELOITTE, 2009; PORTUGAL, 2009a; ORGANISATION FOR ECONOMIC CO-OPERATION AND DEVELOPMENT, 2009). De acordo com o decreto que regulamentava a avaliação do desempenho docente, as escolas dispunham de um prazo de 20 dias úteis para a aprovação dos seus instrumentos de registo do Decreto Regulamentar n. ${ }^{\circ} 2 /$ 2008 (PORTUGAL, 2008a). Posteriormente, foram ainda sendo introduzidas alterações legais e simplificações ao processo de avaliação o que, do ponto de vista das escolas, causou instabilidade e não permitiu uma apropriação gradual do modelo que, no seu entender, é demasiado burocrático.

0 "tempo consumido" constituiu um dos argumentos mais utilizados na contestação ao modelo de avaliação. 0 estudo realizado pela Deloitte (2009) focou este aspecto e concluiu que, globalmente, houve um aumento do número de horas de trabalho para todos os intervenientes no processo. Este trabalho extra foi identificado como decorrente da operacionalização do modelo (não obstante ser expectável que o número de horas dedicado ao processo de avaliação diminuisse nos ciclos seguintes). Todavia, saliente-se que as referências dos professores ao aumento do volume de trabalho não se centraram apenas em aspectos relacionados com o processo de avaliação mas também na imposição, no horário do professor, de um conjunto de tarefas a realizar na "componente não lectiva de estabelecimento" do Decreto-Lei n. ${ }^{\circ}$ 15/2007 (PORTUGAL, 2007b, art. 82..$^{\circ}$, situação que se manteve no Decreto-Lei n. ${ }^{\circ}$ 75/ 2010 (PORTUGAL, 2010b). Esta situação foi, igualmente, geradora de um clima de contestação que dificultou a aceitação do processo de avaliação (PORTUGAL, 2009a).

A construção dos instrumentos de registo, de acordo com o relatório do CCAP (PORTUGAL, 2010a), constituiu uma das principais dificuldades de operacionalização do modelo de avaliação. A generalidade das escolas tentou construir instrumentos próprios, mas a publicação das fichas de avaliação definidas pelo Ministério da Educação exerceu uma influência preponderante no resultado final deste trabalho que, de acordo com a Deloitte (2009), levou as escolas à mera duplicação do trabalho já realizado pelo Ministério da Educação, ao acréscimo da complexidade dos instrumentos e ao acréscimo da burocracia do processo. As escolas ter-se-ão preocupado mais com a padronização de instrumentos tendo em vista a finalidade de tornar objectivo o processo de avaliação. Centraram esforços na discussão e reformulação de itens de avaliação e nas ponderações e aritméticas que deveriam constar nos instrumentos de registo.

A abordagem normativa dominante nas escolas relegou para segundo plano a componente formativa da avaliação preconizada pela legislação, conduzindo à situação em que, de acordo com as observações feitas pelas escolas, a avaliação não tem impacto sobre a melhoria do desempenho, no reconhecimento do mérito e da qualidade dos docentes, na melhoria dos resultados dos alunos ou na melhoria da 
escola como organização (PORTUGAL, 2009a, 2010a). Neste âmbito, o enquadramento dos princípios orientadores do Sistema Integrado da Avaliação do Desempenho na Administração Pública (Siadap) na avaliação do desempenho docente, com a consequente aplicação do sistema de percentagens máximas na distinção do mérito, veio contribuir para a necessidade que as escolas sentiram de objectivar a avaliação através dos instrumentos de registo, centrando nestes o peso do rigor e transparência do processo, chegando-se ao ponto em que falar de "avaliação do desempenho" era sinónimo de "construção de instrumentos de registo".

Durante este $1^{\circ}$ ciclo de avaliação do desempenho docente, foram também identificadas algumas situações que se revelaram facilitadores do processo de avaliação. Nas escolas em que havia um clima de confiança no Conselho Executivo/Director e nos docentes que constituiam a Comissão de Coordenação da Avaliação do Desempeno (CCAD) ou em que pré-existia uma cultura de avaliação, quer devido ao envolvimento do corpo docente em práticas de autoavaliação de escola ou de avaliação externa, quer por haver um maior envolvimento em projectos (como o projecto da "Gestão Flexível do Currículo"), "foi visivel uma menor resistência, bem como maior agilidade e facilidade em desenvolver o processo e resolver conflitos decorrentes da avaliação do desempenho docente" (PORTUGAL, 2009a, p. 13). Percebe-se assim que a confiança nos órgãos de direç̧ão e nos órgãos responsáveis pela organização do processo é condição essencial para o desenvolvimento de uma cultura de avaliação nas escolas. Sem a existência e o reconhecimento desta(s) liderança(s), a avaliação acaba por ser conotada com a instituição de um processo burocrático destinado a impedir que os professores ascendam ao topo da carreira (ORGANISATION FOR ECONOMIC CO-OPERATION AND DEVELOPMENT, 2009).

A quase inexistente cultura de avaliação de desempenho docente nas escolas (bem como as debilidades da própria avaliação institucional) constituiu uma das fragilidades do sistema. São poucos os momentos em que se reflecte sobre a práti-

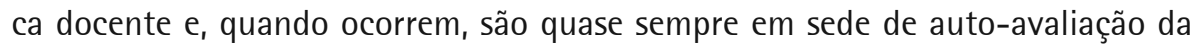
escola e a propósito dos fracos resultados dos alunos. Os processos de supervisão ocorrem quase exclusivamente no contexto da formação inicial dos docentes, cimentando-se assim a ligação da avaliação ao controlo, à penalização e à exclusão (CLímACO, 2008) em detrimento do desenvolvimento profissional.

O clima em que decorreu a aplicação do $1 .^{\circ}$ ciclo de avaliação de desempenho docente sofreu a influência de factores que condicionaram a sua operacionalização. Os estudos realizados (DELOITTE, 2009; PORTUGAL, 2009a; ORGANISATION FOR ECONOMIC CO-OPERATION AND DEVELOPMENT, 2009) revelam que embora exista um largo consenso sobre a necessidade de uma avaliação de professores com consequências, este foi um dos aspectos contestados no modelo de avaliação vigente. 
Se diversos factores de contexto em que o modelo de avaliação emergiu dificultaram a sua implementação, maiores constrangimentos resultaram da falta de reflexão interna e de uma cultura de avaliação fortemente ligada a processos de prestação de contas. As práticas de desenvolvimento profissional têm estado profundamente ligadas às acções de formação proporcionadas pelos Centros de Formação de Associação de Escolas em detrimento de práticas de formação centrada nas necessidades do docente e da escola, predominando a ausência de momentos de reflexão e de partilha do conhecimento profissional adquirido. No que concerne à supervisão pedagógica, esta tem ocorrido, quase exclusivamente, no âmbito da formação inicial dos docentes (ORGANISATION FOR ECONOMIC CO-OPERATION AND DEVELOPMENT, 2009).

\section{Alterações ao modelo de avaliação: o período 2009-2011}

No final do $1^{\circ}$ ciclo de avaliação do desempenho docente (2007-2009) perspectivava-se uma revisão do Estatuto da Carreira Docente (ECD) e do regime de avaliação neste previsto. 0 Decreto-Lei n. ${ }^{\circ}$ 75/2010 (PORTUGAL, 2010b), procede à décima alteração do ECD dando resposta a alguns anseios dos professores, nomeadamente no que respeita ao fim da categoria de professor titular. Houve também algumas alterações ao regime de avaliação do desempenho que passou a estar legislada pelo Decreto Regulamentar n. ${ }^{\circ}$ 2/2010 (PORTUGAL, 2010c).

Os princípios e objetivos do regime de avaliação do desempenho docente agora revisto continuam a ter por base o Sistema Integrado de Avaliação do Desempenho na Administração Pública (Siadap), nomeadamente no que respeita à sua utilização como instrumento de promoção da excelência qualidade dos serviços prestados, bem como a diferenciação do mérito através de um sistema de percentagens máximas para a atribuição das menções qualitativas superiores. As alterações introduzidas fazem-se notar essencialmente ao nível dos procedimentos e organização do processo de avaliação em cada escola. 0 Quadro 2 apresenta uma súmula da organização do regime de avaliação vigente neste período (2009-2011) comparando-o com o realizado no $1 .{ }^{\circ}$ ciclo (2007-2009). 
Quadro 2: Procedimentos a observar na Avaliação do Desempenho Docente.

\begin{tabular}{|c|c|c|}
\hline & $\begin{array}{l}\text { Decreto Regulamentar n. }{ }^{\circ} 2 / 2008 \text {, de } 10 \text { de } \\
\text { Janeiro }\end{array}$ & $\begin{array}{l}\text { Decreto Regulamentar n. } 2 / 2010 \text {, de } 23 \text { de } \\
\text { Junho }\end{array}$ \\
\hline $\begin{array}{l}\text { Dimensões da } \\
\text { avaliação }\end{array}$ & \multicolumn{2}{|c|}{$\begin{array}{l}\text { - Vertente profissional social e ética; } \\
\text { - Desenvolvimento do ensino e da aprendizagem; } \\
\text { - Participação na escola e relação com a comunidade escolar; } \\
\text { - Desenvolvimento e formação pessoal ao longo da vida. }\end{array}$} \\
\hline Periodicidade & \multicolumn{2}{|l|}{2 anos } \\
\hline $\begin{array}{l}\text { Intervenientes } \\
\text { no processo }\end{array}$ & $\begin{array}{l}\text { - Avaliado; } \\
\text { - Comissão Coordenadora da Avaliação do } \\
\text { Desempenho; } \\
\text { - Avaliadores: coordenador de departamento } \\
\text { curricular ou professor titular da área disciplinar } \\
\text { do avaliado; e o director da escola; } \\
\text { - Opcionalmente, poderia ser requerida a } \\
\text { apreciação dos pais e encarregados de educação. }\end{array}$ & $\begin{array}{l}\text { - Avaliado; } \\
\text { - Comissão Coordenadora da Avaliação do } \\
\text { Desempenho; } \\
\text { - Avaliadores: relator (professor da mesma } \\
\text { área disciplinar com posicionamento e } \\
\text { grau académico superior ao avaliado e ser } \\
\text { detentor de formação especializada em } \\
\text { avaliação do desempenho, sempre que } \\
\text { possivel); e júri de avaliação. }\end{array}$ \\
\hline $\begin{array}{l}\text { Elementos de } \\
\text { referência da } \\
\text { avaliação }\end{array}$ & $\begin{array}{l}\text { - Objectivos e metas definidas no Projectos } \\
\text { Educativo e Plano Anual de Actividades da } \\
\text { escola; } \\
\text { - Indicadores de medida estabelecidos pela } \\
\text { escola relativos aos resultados dos alunos e } \\
\text { abandono escolar; } \\
\text { - Objectivos fixados no Projecto Curricular de } \\
\text { Turma (opcional). }\end{array}$ & $\begin{array}{l}\text { - Padrões de Desempenho Docente } \\
\text { estabelecidos a nível nacional; } \\
\text { - Objectivos e metas definidas no Projectos } \\
\text { Educativo e Plano Anual de Actividades da } \\
\text { escola; } \\
\text { - Objectivos Individuais, quando } \\
\text { apresentados (opcional). }\end{array}$ \\
\hline $\begin{array}{l}\text { Objectivos } \\
\text { Individuais }\end{array}$ & Apresentação obrigatória. & Apresentação facultativa. \\
\hline $\begin{array}{l}\text { Observação de } \\
\text { aulas }\end{array}$ & $\begin{array}{l}\text { - Obrigatória para todos os professores; } \\
\text { - } 3 \text { aulas em cada ano do ciclo de avaliação. }\end{array}$ & $\begin{array}{l}\text { - Obrigatória apenas para os professores } \\
\text { que se encontra na transição para o } 3 .^{\circ} \text { e } \\
5 .^{\circ} \text { escalão da carreira docente; } \\
\text { - } 2 \text { aulas em cada ano do ciclo de avaliação; } \\
\text { - Condição necessária para ascender às } \\
\text { menções de muito bom e excelente. }\end{array}$ \\
\hline $\begin{array}{l}\text { Instrumentos } \\
\text { de registo }\end{array}$ & $\begin{array}{l}\text { - Elaborados e aprovados pelo Conselho } \\
\text { Pedagógico tendo em conta as recomendações } \\
\text { do Conselho Científico para a Avaliação de } \\
\text { Professores (órgão nacional). }\end{array}$ & $\begin{array}{l}\text { - Elaborados pela Comissão Coordenadora da } \\
\text { Avaliação do Desempenho e aprovados pelo } \\
\text { Conselho Pedagógico tendo em conta os } \\
\text { Padrões de Desempenho Docente e as } \\
\text { recomendações do Conselho Científico para a } \\
\text { Avaliação de Professores (órgão nacional). }\end{array}$ \\
\hline $\begin{array}{l}\text { Auto- } \\
\text { avaliação }\end{array}$ & $\begin{array}{l}\text { - Obrigatória. Deve explicitar o contributo do } \\
\text { docente para o cumprimento dos objectivos } \\
\text { individuais fixados. }\end{array}$ & $\begin{array}{l}\text { Obrigatória. Deve realizar-se de acordo com as } \\
\text { regras e padrões de uniformização definidos } \\
\text { pelo Ministério da Educação. }\end{array}$ \\
\hline $\begin{array}{l}\text { Entrevista } \\
\text { individual }\end{array}$ & $\begin{array}{l}\text { Obrigatória. Tem por objectivo dar conhecimento } \\
\text { da proposta de avaliação e proporcionar } \\
\text { oportunidade para a sua apreciação conjunta, } \\
\text { bem como a análise da ficha de auto-avaliação. }\end{array}$ & $\begin{array}{l}\text { Facultativa. Deve ser requerida pelo } \\
\text { avaliado após ter conhecimento da } \\
\text { proposta de avaliação e tem por objectivo } \\
\text { a apreciação conjunta dos elementos do } \\
\text { processo de avaliação. }\end{array}$ \\
\hline $\begin{array}{l}\text { Resultados do } \\
\text { processo de } \\
\text { avaliação }\end{array}$ & \multicolumn{2}{|c|}{$\begin{array}{l}\text { Expressos através de } 5 \text { menções qualitativas: Excelente; Muito Bom; Bom; Regular e Insuficiente. } \\
\text { As duas menções superiores estão sujeitas a percentagens máximas na sua atribuição. }\end{array}$} \\
\hline
\end{tabular}

Fonte: Os autores (2011). 
As dimensões da avaliação, no $1 .^{\circ}$ ciclo (2007-2009), eram aferidas de acordo com duas componentes do desempenho docente - científico-pedagógica e funcional - e apreciadas pelo coordenador de departamento curricular e pelo director da escola, respectivamente. De acordo com o novo regime (2009-2011), as quatro dimensões da avaliação concretizam-se num conjunto de domínios, explicitados no art. ${ }^{0} 45 .^{\circ}$ do Decreto-Lei n. ${ }^{\circ} 75 / 2010$ (PORTUGAL, 2010b), que deverão ser apreciados, na sua totalidade, pelo relator (avaliador), embora a classificação seja da responsabilidade do júri de avaliação (PORTUGAL, 2010c).

Uma vez que a revisão do Estatuto da Carreira Docente (PORTUGAL, 2010b) pôs fim à categoria de professor titular, a designação dos avaliadores/relatores assumiu regras diferentes, a saber: o relator deverá ser do mesmo grupo de recrutamento do professor avaliado, sempre que possivel possuir grau académico e posicionamento na carreira superior e deve, preferencialmente, possuir formação especializada em avaliação do desempenho docente.

Intervêm, ainda, no processo de avaliação a CCAD e o Júri de Avaliação. À CCAD compete a organização do processo de avaliação na escola e a construção dos instrumentos de registo da avaliação. Compete ao Júri de Avaliação, composto pela CCAD e pelo relator, entre outras funções, proceder à atribuição fundamentada da classificação final do professor avaliado, com base na proposta de classificação apresentada pelo relator. Em todo este processo deixou de estar prevista uma possivel participação dos encarregados de educação na avaliação dos professores.

A construção dos instrumentos de registo deverá ser feita tendo em conta os Padrões de Desempenho Docente definidos a nivel nacional, bem como as orientações do CCAP'1.

Os Padrões de Desempenho Docente constituem ainda um dos elementos de referência da avaliação, junto com os objectivos e metas do Projecto Educativo e Plano Anual de Actividades da escola e os Objectivos Individuais (sempre que o professor opte pela sua definição). Os indicadores de medida relativos aos resultados dos alunos e ao abandono deixaram de ser considerados como elemento de referência da avaliação.

\footnotetext{
10 CCAP, criado pelo Decreto-Lei n. ${ }^{\circ}$ 15/2007 (PORTUGAL, 2007b), de 19 de Janeiro, é um órgão nacional que tem por missão implementar e assegurar o acompanhamento e a monitorização do regime de avaliação do desempenho do pessoal docente da educação pré-escolar e dos ensinos básico e secundário. 0 Decreto Regulamentar n. ${ }^{4}$ /2008, de 5 de Fevereiro, define o CCAP como órgão consultivo do Ministério da Educação, dotado de autonomia técnica e científica, com a atribuição de formular recomendações, orientações, pareceres e propostas que, tendo por referência o conhecimento consolidado e a informação actualizada na área da sua intervenção, contribuam para: fundamentar decisões e procedimentos em matéria de avaliação de desempenho do pessoal docente; promover a adequada aplicação e utilização do sistema de avaliação de desempenho do pessoal docente; fomentar uma cultura de avaliação docente e de desenvolvimento profissional. Sobre o assunto, bem como os diversos materiais produzidos, ver o sítio do CCAP em: http://www.ccap.min-edu.pt/.
} 
Embora a observação de aulas seja agora um procedimento facultativo, este constitui condição necessária para a obtenção das menções qualitativas de Muito Bom e Excelente, bem com para a progressão ao $3 .^{\circ}$ e $5 .^{\circ}$ escalão da carreira docente.

A auto-avaliação mantém-se como procedimento obrigatório e concretiza-se através de um relatório a entregar ao relator (este relatório é apresentado de acordo com as regras definidas no Despacho n. ${ }^{0}$ 14.420/2010 (PORTUGAL, 2010d).

A entrevista individual, prevista no anterior regime de avaliação, destinada à apreciação conjunta do desempenho docente, bem como da proposta de avaliação, deixa de ser um procedimento obrigatório, passando a decorrer apenas por requerimento do avaliado. Porém, sempre que haja lugar à observação de aulas, o relator e o professor avaliado deverão reunir com o objectivo de proceder à apreciação conjunta das aulas observadas (PORTUGAL, 2010c).

A atribuição das menções qualitativas tem como referente os Padrões de Desempenho Docente (PORTUGAL, 2010e), é expressa de acordo com 5 niveis (Insuficiente, Regular, Bom, Muito Bom, Excelente) e têm correspondência numa escala quantitativa de 1 a 10 valores. A atribuição das menções qualitativas superiores, Muito Bom e Excelente, está sujeita a um regime de percentagens máximas atribuídas a cada escola, tendo em conta os resultados obtidos na avaliação externa (PORTUGAL, 2011b). Ainda no que diz respeito à atribuição da menção qualitativa Excelente, esta deve ser acompanhada de uma justificação que especifique o contributo do docente para 0 sucesso escolar dos alunos e para a qualidade das suas aprendizagens, com vista à sua utilização numa base de dados sobre boas práticas (PORTUGAL, 2010b).

Decorrente da aplicação das percentagens relativas à diferenciação dos desempenhos e como forma de "premiar o mérito e a excelência" existe um sistema de recompensas cujos efeitos se fazem sentir, essencialmente, ao nivel da progressão na carreira docente. Assim, a atribuição das menções qualitativas superiores (Muito Bom e Excelente) confere o direito à progressão ao $5 .^{\circ}$ e $7 .^{\circ}$ escalão da carreira docente independentemente da existência de vagas. A atribuição de duas menções qualitativas superiores consecutivas resulta na bonificação de 6 meses ou 1 ano de tempo de serviço para efeitos de progressão na carreira. A atribuição da menção qualitativa Bom permite 0 acesso à carreira, bem como a normal progressão. No caso da atribuição das menções qualitativas Regular e Insuficiente determina-se a não contagem do período a que respeita a avaliação para efeitos de progressão na carreira (PORTUGAL, 2010b).

Embora tenham sido introduzidas diversas alterações ao regime de avaliação do desempenho docente (neste período de 2009-2011), sobretudo ao nível da implementação do dispositivo, os seus princípios, finalidades e objectivos permaneceram os mesmos (em comparação com o regime anterior de 2007-2009). 
Ainda que no momento (Junho de 2011) não se possa realizar uma análise sistemática do deste segundo ciclo de avaliação (pois este prolonga-se até Dezembro de 20112), de acordo com o relatório do CCAP (PORTUGAL, 2011a), correspondente ao primeiro ano de implementação, permanecem várias dificuldades na sua operacionalização nas escolas, não se reconhecendo que a avaliação tenha tido impacto no desenvolvimento profissional e na melhoria das práticas docentes. Questões relativas à nomeação e legitimação dos avaliadores, bem como à (ausência) formação especializada para o desempenho desta função permanecem como problemas que dificultaram o "desenvolvimento de uma cultura de colaboração e de criação de mecanismos de supervisão construtiva entre pares" (PORTUGAL, 2011a, p. 28). Apesar da maior aceitação do modelo de avaliação de desempenho docente e de se terem mobilizado aprendizagens decorrentes do $1 .{ }^{\circ}$ ciclo de avaliação, o relatório do CCAP (PORTUGAL, 2011a, p. 28) aponta para o facto de as mudanças terem ocorrido mais ao nível da "morfologia organizacional (aceitação e execução de regulamentos) do que da efectiva mudança de práticas".

\section{As dimensões formativa e sumativa do modelo de avaliação}

Do ponto de vista do discurso político-normativo, o modelo de avaliação do desempenho docente vigente em Portugal entre 2007 e 2011 apresentou como principios orientadores a melhoria da qualidade do serviço educativo e das aprendizagens dos alunos, bem como a contribuição para o desenvolvimento pessoal e profissional dos docentes no quadro de um sistema de reconhecimento do mérito e da excelência (PORTUGAL, 2010b).

Contudo, se, por um lado, os objectivos do modelo de avaliação se anunciam enfatizando os processos de desenvolvimento profissional como forma de promover a qualidade do serviço educativo e das aprendizagens dos alunos, por outro lado, os efeitos da avaliação de professores fazem-se sentir na carreira, nomeadamente no acesso e na progressão, sendo esta uma das vias encontradas para premiar o mérito e a excelência.

Assim, a avaliação do desempenho apresenta-se como um mecanismo de desenvolvimento profissional do pessoal docente, associado a um dispositivo de prestação de contas e de recompensas para os melhores profissionais. 0 quadro 3 mostra os objectivos da avaliação do desempenho de acordo com estas duas dimensões.

20 ciclo de avaliação termina em 31 de Agosto, os procedimentos de classificação, reclamação e recurso da avaliação podem prolongar-se até Dezembro, conforme a calendarização de cada escola. 
Quadro 3: Objectivos da Avaliação do Desempenho Docente (n. 3 do art. $40 .^{\circ}$ do Decreto Lei n. ${ }^{0}$ 75/2010, de 23 de Junho).

\begin{tabular}{|c|c|}
\hline Desenvolvimento profissional & Sistema de Recompensas e Prestação de Contas \\
\hline \multicolumn{2}{|c|}{$\begin{array}{l}\text { Contribuir para a valorização do trabalho e da profissão docente; Detectar } \\
\text { os factores que influenciam o rendimento profissional do pessoal docente; }\end{array}$} \\
\hline $\begin{array}{l}\text { Contribuir para a melhoria da prática } \\
\text { pedagógica docente; Permitir a inventariação } \\
\text { das necessidades de formação do pessoal } \\
\text { docente; Promover o trabalho de cooperação } \\
\text { entre os docentes, tendo em vista a melhoria } \\
\text { do seu desempenho; Promover um processo } \\
\text { de acompanhamento e supervisão } \\
\text { da prática docente. }\end{array}$ & $\begin{array}{l}\text { Diferenciar e premiar os melhores profissionais; } \\
\text { Facultar indicadores de gestão em matéria de } \\
\text { pessoal docente; Promover a responsabilização } \\
\text { do docente quanto ao exercício da sua } \\
\text { actividade profissional. }\end{array}$ \\
\hline
\end{tabular}

Fonte: Os autores (2011).

De acordo com esta perspectiva, o modelo de avaliação oscila entre dois pólos, a avaliação formativa, associada a mecanismos de desenvolvimento profissional, e a avaliação sumativa, mais aliada a mecanismos de prestação de contas, conforme esquematizado na Figura 2.

Figura 2: Modelo de avaliação do desempenho docente.

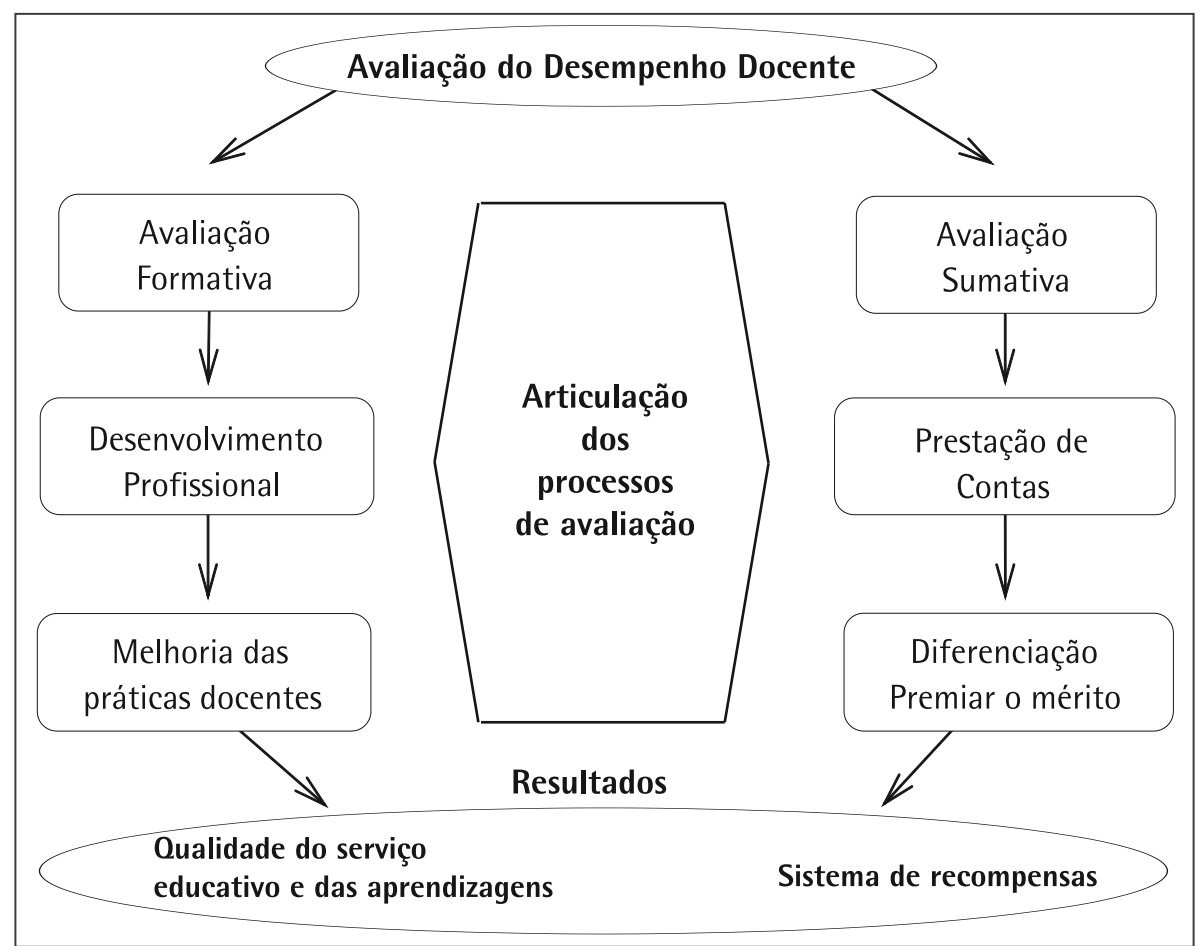

Fonte: Os autores (2011). 
A avaliação de cariz formativo é realizada ao longo do processo e de modo contínuo, produz informação sobre o desempenho dos professores visando a melhoria das práticas e, entre outros aspectos, permite identificar as necessidades de formação dos docentes. A sua implementação nas escolas pressupõe trabalho colaborativo, bem como acompanhamento e supervisão, de modo a potenciar as qualidades dos professores, permitindo ultrapassar as suas dificuldades e contribuindo para a melhoria da qualidade da escola.

A avaliação sumativa tem lugar, normalmente, no final do processo, com 0 intuito de verificar o grau de concretização dos objectivos propostos, baseia-se na informação recolhida sobre o desempenho docente e visa a classificação, permitindo a diferenciação dos desempenhos.

É perante esta dicotomia avaliação formativa - avaliação sumativa que as escolas têm levado a cabo a operacionalização do modelo de avaliação. Se é legítimo, e porventura pertinente, que num mesmo modelo coexistam estes dois propósitos, todavia, na prática, tem-se verificado todo um conjunto de dificuldades no que se reporta à sua exequibilidade. Se não se pode escamotear o facto de que a regulamentação do modelo de avaliação enuncia um conjunto de objectivos que valorizam a componente formativa, também não se pode deixar de reconhecer que, ao mesmo tempo, se condiciona a acção das escolas no sentido da valorização da componente sumativa dado que todo o dispositivo é pensado em função da classificação final do docente. A ambiguidade existente entre os objectivos enunciados e o dispositivo de avaliação prescrito conduz à preocupação (legítima) por parte dos professores com o processo de avaliação e respectiva construção dos instrumentos de registo. Assim, valoriza-se o controlo e a quantificação e dirige-se a atenção para a objectividade na verificação e na medição das competências dos docentes. Transforma-se, desta forma, a avaliação do desempenho numa questão técnica remetendo-se para segundo plano o acompanhamento e o trabalho colaborativo. Assim, se se pretende que a avaliação do desempenho possa actuar como estímulo à melhoria da prática docente, tal como preconizado na regulamentação do modelo, torna-se necessário que o processo seja coerente com este princípio.

\section{Considerações finais}

0 modelo de avaliação do desempenho docente vigente em Portugal (2007-2011) tem-se vindo a confrontar quer com a promoção do desenvolvimento profissional dos professores e consequente melhoria das suas práticas, quer com a medição e o controlo do seu desempenho. Se os objectivos expressos do modelo acentuam o desenvolvimento profissional, toda a regulamentação do processo tem assentado em aspectos tecnicistas dirigidos para a expressão final da avaliação, isto é, para a classificação. Também, por parte de muitas escolas, não terão existido suficientes espaços para um debate participado, pacificado e devidamente informado sobre estas questões, numa reflexão conjunta e partilhada que fosse criando condições para alicerçar uma cultura de avaliação. 
A avaliação do desempenho docente em Portugal surgiu como medida imposta externamente pelo poder político, mas a sua execução é interna, ou seja, são as escolas, os directores, os professores avaliadores e avaliados que a têm que aplicar. Ora, num cenário deste tipo e tendo em vista o sucesso da medida, torna-se essencial prestar atenção, ente outros factores, ao ambiente em que esta está a ser promovida. Reportando-se a vários estudos, Flores (2009) salienta que, na implementação de medidas complexas como a avaliação do desempenho docente, há que considerar aspectos como: a diversidade dos contextos em que vão ocorrer as mudanças, o reconhecimento dos avaliadores, a adequação dos instrumentos de avaliação, a importância do feedback, o papel do Director da escola, os actores envolvidos no processo, designadamente a forma como sentem e interpretam as medidas políticas, assim como o seu quadro de valores.

Se não forem criadas oportunidades para que os professores desenvolvam formação adequada em matéria de avaliação do desempenho, parece pouco provável que o modelo de avaliação cumpra os objectivos previstos. A mobilização de concepções e conhecimentos pré-existentes, nomeadamente no que respeita à associação da avaliação ao controlo, e a falta de análise e debate, sereno e sustentado, em torno da avaliação do desempenho docente geram dificuldades na compreensão e na concretização do modelo e, sobretudo, na gestão dos equilibrios entre os diferentes propósitos da avaliação.

A operacionalização em Portugal deste modelo de avaliação do desempenho docente (2007-2011) tem, ainda, sido condicionada pela tradição das práticas docentes e pela visão que os professores tinham de uma carreira que era linear e imutável. Uma vez integrado na carreira, o professor teria apenas que deixar passar o tempo para conseguir a normal progressão e pouco teria que fazer para a consecução do seu desenvolvimento profissional. 0 modelo de avaliação que tem vindo a ser posto em prática impõe uma maior responsabilização e uma atitude mais activa do professor, exigindo que este mantenha os seus conhecimentos actualizados, que os utilize na sua prática lectiva, que promova o seu desenvolvimento - tendo em conta a consecução das aprendizagens qualificadas dos alunos e o desenvolvimento da escola como organização. 


\section{Referências}

BENAVOT, A.; RESNIK, J. Lessons from the past: a comparative socio-historical analysis of primary and secondary education. In: BENAVOT, A.; RESNIK, J.; CORRALES, J. Global education expansion: historical legacies and political obstacles. Cambridge: American Academy of Arts and Sciences, 2006. Disponível em: <http://www.amacad.org/publications/benavot.pdf>. Acesso em: 15 out. 2010.

BILHIM, J. Metodologia e técnicas de avaliação. In: ENCONTRO DO INSTITUTO NACIONAL DE ADMINISTRAÇÃO, 1., 1998, Oeiras. Avaliação na administração pública: anais... Oeiras, PT: Instituto Nacional de Administração, 1998. p. 125-132.

BOUCKAERT, G. Medição e gestão da performance no contexto do sector público. In: ENCONTRO DO INSTITUTO NACIONAL DE ADMINISTRAÇÃOAVALIAÇÃO NA ADMINISTRAÇÃO PÚBLICA, 1. 1998, Oeiras. Anais... Oeiras: Instituto Nacional de Administração, 1998. p. 57-72.

CLÍMACO, M. C. Comentários à intervenção de Gérard Figari. In: RAMOS, C. C. Avaliação de professores: visões e realidades.In: CONFERÊNCIA INTERNACIONAL, 1998, Lisboa. Avaliação de professores visões e realidades: actas... Lisboa: ME, CCAP, 2008. p. 27-31. Disponível em: <http://www.ccap.min-edu.pt/docs/ Actas_Conf_Aval_Prof-2007.pdf>. Acesso em: 1 set. 2010.

CURAD0, A. P. Políticas de avaliação de professores em Portugal: um estudo de implementação. Lisboa: Fundação Calouste Gulbenkian, 2004.

DELOITTE. Estudo de impacto do Modelo de Avaliação dos Docentes. Lisboa: ME, 2009. Disponivel em: <http://www.min-edu.pt/np3content/?newsld=2829\&fileName=estudo_ impacto_relatorioFinal.pdf> Acesso em: 18 jun. 2010.

FLORES, M. A. Avaliação de professores: reflexões sobre o caso português. Revista Iberoamericana de Evaluación Educativa, Lisboa, v. 2, n. 1, p. 240-256, 2009. Disponivel em: <http://www.rinace.net/riee/numeros/vol2-num1/ art13.pdf>. Acesso em: 2 nov. 2010.

FORMOSINHO, J.; MACHADO, J. Os professores e a diferenciação docente: da especialização de funções à avaliação do desempenho. In: FORMOSINHO, J.; MACHADO, J.; OLIVEIRA-FORMOSINHO, J. Formação, desempenho e avaliação de professores. Mangualde: Edições Pedago, 2010. p. 77-95.

GAMEIRO, M. A Avaliação na administração pública: actores e papéis. In: ENCONTRO DO INSTITUTO NACIONAL DE ADMINISTRAÇÃO, , 1. 1998, Oeiras. Avaliação na administração pública: anais... Oeiras, PT: Instituto Nacional de Administração, 1998. p. 117-124. 
LASCOUMES, P.; LE GALĖS, P. Sociologie da l'action publique. Paris: Armand Colin, 2007.

ORGANISATION FOR ECONOMIC CO-OPERATION AND DEVELOPMENT. Teacher

Evaluation in Portugal. OECD Review, 2009. Disponivel em: <http://

www.oecd.org/dataoecd/17/32/43327186.pdf>. Acesso em: 28 jun. 2009.

PORTUGAL. Assembleia da República. Lei no. 46, de 14 de outubro de 1986. A presente lei estabelece o quadro geral do sistema educativo, com alterações introduzidas pela Lei n. ${ }^{\circ} 49 / 2005$, de 30 de Agosto de 2005. Diário da República, Lisboa, n. 237, 14 out. 1986. Série 1. Disponivel em: <http://www.dges.mctes.pt/ NR/rdonlyres/283BAF87-01C8-4EF4-A169-694533E63B0D/612/ LeideBases4686.pdf>. Acesso em: 8 set. 2011.

PORTUGAL. Lei $\mathrm{n}^{\circ} 10$, de 22 de março de 2004. A presente lei cria o sistema integrado de avaliação do desempenho da Administração Pública, adiante designado por SIADAP, o qual integra a avaliação de desempenho dos funcionários, agentes e demais trabalhadores, dos dirigentes de nível intermédio e dos serviços e organismos da administração directado Estado e dos institutos públicos, com alterações introduzidas pela Lei no 66-B/2007 de 28 de Dezembro. Diário da República, Lisboa, n. 69, 22 mar. 2004. Série 1-A. Disponivel em: $<$ http://intranet.uminho.pt/Arquivo/Legislacao/AvaliacaoDesempenho/ L_10_2004.pdf>. Acesso em: 8 set. 2011.

PORTUGAL. Lei nº. 49, de 30 de Agosto de 2005. Segunda alteração à Lei de Bases do Sistema Educativo e primeira alteração à Lei de Bases do Financiamento do Ensino Superior. Diário da República, Lisboa, n. 166, 30 ago. 2005. I Série-A, p. 5.122-5.138. Disponivel em: <http://dre.pt/pdf1s/2005/08/166A00/ 51225138.pdf>. Acesso em: 8 set. 2011.

. Lei $n^{0}$. 66-B, de 28 de dezembro de 2007. Estabelece o sistema integrado de gestão e avaliação do desempenho na Administração Pública. Diário da República, Lisboa, n. 250, 28 dez. 2007a. 1ª. Seção, p. 9.114-(2)-(21). disponivel em: <http://www.itn.pt/pt/leis/250IA07-L66B.pdf>. Acesso em: 8 set. 2011.

PORTUGAL. Ministério da Educação. Conselho Científico para a Avaliação de Professores. Relatório anual 2010 sobre o processo de avaliação do desempenho docente. Lisboa: Ministério da Educação/CCAP, 2011a. Disponível em: <http:// www.ccap.min-edu.pt/docs/Rel_anual_ADD_2010.pdf>. Acesso em: 20 jun. 2011.

- Relatório sobre a aplicação do $1 .^{\circ}$ ciclo de avaliação do desempenho docente. Lisboa: Ministério da Educação/CCAP, 2010a. Disponivel em: <http:// www.ccap.min-edu.pt/docs/Rel_1_ciclo_ADD.pdf>. Acesso em 20 jan. 2011. 
PORTUGAL. Ministério da Educação. Conselho Científico para a Avaliação de Professores. Relatório sobre o acompanhamento e a monitorização da avaliação do desempenho docente na Rede de Escolas Associadas ao CCAP. Lisboa: Ministério da Educação/CCAP, 2009a. Disponivel em: <http://www.ccap.minedu.pt/docs/Rel_Rede_escolas_CCAP-2009.pdf>. Acesso em: 30 set. 2010.

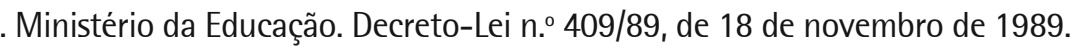
Aprova a estrutura da carreira do pessoal docente da educação pré-escolar e dos ensinos básico e secundário e estabelece as normas relativas ao seu estatuto remuneratório. Diário da República, Lisboa, n. 266, 18 nov. 1989. Série 1. Disponivel em: < http://dre.pt/pdfgratis/1989/11/26601.pdf>. Acesso em: 08/09/2011.

PORTUGAL. Ministério da Educação.Decreto-Lei n.o 139-A/90, de 28 de abril de 1990. Aprova o estatuto da carreira dos educadores de infância e dos professores dos Ensinos básico e secundário. Diário da República, Lisboa, n. 98, 28 abr. 1990. Série 1-A. Disponivel em: < http://dre.pt/pdfgratis/1990/04/09801.pdf>. Acesso em: 8 set.2011.

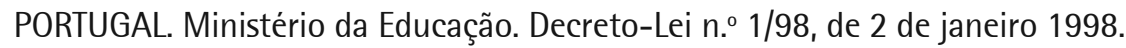
Altera o estatuto da carreira dos educadores de infância e dos professores dos Ensinos Básico e Secundário, aprovado pelo Decreto-Lei n.o 139-A/90, de 28 de Abril de 1990. Diário da República, Lisboa, n. 1, 02 jan. 1998a. Série 1-A. Disponível em: <http://dre.pt/pdfgratis/1998/01/001A00.pdf>. Acesso em: 08/09/2011.

Ministério da Educação.Decreto-Lei n. ${ }^{\circ}$ 312/99, de 10 de agosto 1999. Aprova a estrutura da carreira de pessoal docente de educação pré-escolar e dos ensinos básico e secundário e estabelece as normas relativas ao seu estatuto remuneratório. Diário da República, Lisboa, n. 185, 10 ago. 1999. Série 1-A. Disponivel em: < http://dre.pt/ pdfgratis/1999/08/185A00.pdf>. Acesso em: 8 set. 2011.

PORTUGAL. Ministério da Educação. Decreto-Lei n. ${ }^{\circ}$ 15/2007, de 19 de janeiro 2007. Sétima alteração do Estatuto da Carreira dos educadores de infância e dos professores dos ensinos Básico e Secundário, aprovado pelo Decreto-Lei n.o 139A/90, de 28 de Abril, e altera o regime jurídico da formação contínua de professores, aprovado pelo Decreto-Lei n.o 249/92, de 9 de Novembro. Diário da República, Lisboa, n. 14, 19 jan. 2007b. Série 1. Disponível em: <http://dre.pt/ pdfgratis/2007/01/01400.pdf>. Acesso em: 8 set. 2011.

. Ministério da Educação. Decreto-Lei n. 75/2010, de 23 de junho 2010. Procede à décima alteração ao Estatuto da Carreira dos Educadores de Infância e dos Professores dos Ensinos Básico e Secundário, aprovado pelo Decreto-Lei n. ${ }^{\circ}$ 139-A/90, de 28 de Abril. Diário da República, Lisboa, n. 120, 23 jun. 2010b. Série 1. Disponível em: < http://dre.pt/pdfgratis/2010/06/12000.pdf>. Acesso em: 08/09/2011. 
PORTUGAL. Ministério da Educação. Decreto Regulamentar n. ${ }^{\circ}$ 13/92, de 30 de Junho de 1992. Regulamenta o processo de avaliação para o acesso ao $8 .^{\circ}$ escalão da carreira docente do ensino não superior. Diário da República, Lisboa, n. 148, 30 jun. 1992a. Série 1-B. Disponivel em: <http://dre.pt/pdfgratis/1992/06/ 148B04.pdf>. Acesso em: 8 set. 2011.

Ministério da Educação. Decreto Regulamentar n. ${ }^{0}$ 14/92, de 4 de Julho de 1992. Regulamenta o processo de avaliação do desempenho do ensino não superior. Diário da República, Lisboa, n. 152, 4 jul. 1992b. Série 1-B. Disponivel em: < http:// www.dre.pt/pdfgratis/1992/07/152B01.pdf>. Acesso em: 08/09/2011.

Ministério da Educação. Decreto Regulamentar n. ${ }^{0} 11 / 98$, de 15 de maio de 1998. Regulamenta o processo de avaliação do desempenho do pessoal docente da educação pré-escolar e dos ensinos básico e secundário. Diário da República, Lisboa, n. 112, 15 maio 1998b. Série 1-B. Disponivel em: <http:// dre.pt/pdfgratis/1998/05/112B00.pdf>. Acesso em: 08/09/2011.

. Ministério da Educação. Decreto Regulamentar n. ${ }^{0}$ 2/2008, de 10 de janeiro de 2008. Diário da República, Lisboa, n. 7, 10 jan. 2008a. 1. Série, p. 225-233.

. Ministério da Educação. Decreto Regulamentar n. ${ }^{0}$ 2/2010, de 23 de Junho de 2010. Regulamenta o sistema de avaliação do desempenho do pessoal docente da educação pré-escolar e dos ensinos básico e secundário e revoga os Decretos Regulamentares n.os 2/2008, de 10 de Janeiro, 11/2008, de 23 de Maio, 1-A/2009, de 5 de Janeiro, e 14/2009, de 21 de Agosto. Diário da República, Lisboa, n. 120, 23 jun.2010c. Série 1. Disponivel em: < http://dre.pt/pdfgratis/ 2010/06/12000.pdf>. Acesso em: 08/09/2011.

Ministério da Educação. Decreto Regulamentar 1-A/2009, de 5 de Janeiro de 2009. Estabelece um regime transitório de avaliação de desempenho do pessoal a que se refere o Estatuto da Carreira dos Educadores de Infância e dos Professores dos Ensinos Básico e Secundário, aprovado pelo Decreto-Lei n. ${ }^{0}$ 139-A/90, de 28 de Abril. Diário da República, Lisboa, n. 2, 5 jan. 2009b. Série 1. Disponivel em: <http:/ /dre.pt/pdfgratis/2009/01/00201.pdf>. Acesso em: 08/09/2011.

Ministério da Educação. Despacho n. ${ }^{\circ}$ 16.872/2008, de 7 de abril de 2008. Diário da República, Lisboa, n.119, 23 jun. 2008b. 2a série, p. 27.150-27.157. Disponivel em: <dre.pt/pdf2sdip/2008/06/119000000/2715027157.pdf>. Acesso em: 8 set. 2011.

. Ministério da Educação. Despacho nº. 3006/2009, de 23 de Janeiro de 2009. Diário da República, n. 16, 23 jan. 2009c. 2. Série, p. 3.412-3.414. Disponível em: <http://dre.pt/pdf2sdip/2009/01/016000000/0341203414.pdf>. Acesso em: 8 set. 2011. 
PORTUGAL. Ministério da Educação. Despacho n. ${ }^{\circ}$ 14.420/2010, de 15 de Setembro de 2010. Diário da República, Lisboa, n. 180, 15 set. 2010d . Série 2. Disponivel em: < http://dre.pt/pdf2sdip/2010/09/180000000/4713447135.pdf>. Acesso em: 8 set. 2011.

- Ministério da Educação. Despacho n. ${ }^{0} 16.034 / 2010$, de 22 de outubro de 2010. Diário da República, Lisboa, n. 206, 22 out. 2010e. 2a Série, p. 53.300-302. disponivel em: <http://www.ccap.min-edu.pt/docs/Desp_16034-2010.pdf>. Acesso em: 8 set. 2011.

- Ministério das Finanças. Ministério da Administração Pública. Ministério da Educação. Despacho n. ${ }^{\circ}$ 5.464/2011, de 30 de Março de 2011. Altera 0 Estatuto da Carreira dos Educadores de Infância e dos Professores dos Ensinos Básico e Secundário (ECD) operada pelo Decreto -Lei n. ${ }^{\circ}$ 75/2010, de 23 de Junho, e regulamentada pelo Decreto Regulamentar n. ${ }^{\circ}$ 2/2010, de 23 de Junho, procede à modificação do regime da avaliação do desempenho do pessoal docente então em vigor. Diário da República, Lisboa, n. 63, 30 mar. 2011b . Série 2. Disponível em: <http://dre.pt/pdf2sdip/2011/03/063000000/ 1485914859.pdf>. Acesso em: 8 set. 2011.

- Ministério das Finanças. Ministério da Administração Pública. Portaria n. ${ }^{\circ}$ 1.633/2007, de 31 de Dezembro de 2007. Aprova os modelos de fichas de autoavaliação e avaliação do desempenho. Diário da República, Lisboa, n. 251, 31 dez. 2007c. Série 1. Disponível em: < http://dre.pt/pdfgratis/2007/12/25100.pdf>. Acesso em: 8 set. 2011.

SIMÕES, G. A. A avaliação dos professores como estratégia de desenvolvimento profissional e organizacional. Lisboa: Faculdade de Psicologia e Ciências da Educação, 1998.

Recebido em: 02/08/2011

Aceito para publicação em: 05/09/2011 